\title{
Modern approaches to Agile transformation of Russian financial and technological companies
}

\author{
Denis Vorontsov* \\ State University of Yaroslavl named after P.G. Demidov, 14 Sovetskaya Street, Yaroslavl, Russia, 150003
}

\begin{abstract}
The article considers the relevance of the Russian organizations Agile transformation operating in the financial technology industry. The current concepts of Agile-transformation are presented. The experience of implementing Agile transformations in large Russian banks is presented. The current processes occurring during the transformation of fintech companies are presented. The conditions and features of Agile transformation depending on the scale of a fintech company are considered. Changes in the corporate culture are analyzed from the point of view of project teams and the Agile companies as a whole. Approaches to the transformation of the company's organizational structure are presented, with the identification and description of new implemented structural elements and roles. The change in the project methodology of a Fintech company during Agile transformation is presented as a transition, implementation and adaptation of popular Agile frameworks and hybrid project approaches based on the project methodologies of Waterfall, Scrum and SAFe. The current and practical stages of Agile transformation of large fintech companies operating in the banking market are analyzed and described in detail. Assumptions are made about the potential problems caused by the escalating competition, restrictions and consequences caused by the Covid-19 pandemic. Medium-term challenges and prospects for the transition of companies to Agile in the Russian fintech market are presented.
\end{abstract}

\section{Introduction}

The active growth of Russian financial technology industry was provoked by the financial crisis in 2008 . During this time, companies were forced to cut costs and improve efficiency and/or seek new technological solutions. The second significant factor in the development of the industry was the progress of mobile technologies, which allowed people to get round-theclock and prompt access to the Internet. Today it is one of the fastest growing markets both in Russia and in the world. The number of users of financial services and the volume of their supply increase by $15-20 \%$ annually. The volume of payments, transfers, personal and corporate finance is growing by an average of $20 \%$. Russia is in the top 3 countries in terms of the popularity of financial and technological services and penetration level reaches $82 \%$. According to Deloitte estimates, in 2019 the volume of the Russian fintech market amounted to 60 billion rubles. (+11\%), and in 2020 it grew to 65 billion rub $(+8 \%)$.

The slowdown in growth is explained by the high level of uncertainty in new market and the impact of the Covid-19 pandemic. Despite this, analysts predict a twofold growth of the market by 2024 [1].

In order to be successful in this industry, companies must promptly deliver to customers a high-quality product increment, by which we mean a tangible result of one iteration/sprint (for example, an application prototype or an increment of new functionality to a product).

Moreover, it is extremely important to be flexible and be able to respond in a timely manner to feedback received from customers. Consequently, this leads to a transition from a hierarchical organization management structure and waterfall approaches to project management and financing, agile project management approaches and a new organizational structure. Therefore, more and more Russian companies choose agile development as an important financial and technological solution that is successfully integrated in international companies and helps companies win the competition.

Agile companies see significant improvements in key metrics as evidenced by research on productivity, time shifts, defect counts and development costs across 1,321 software development projects in the $10^{\text {th }}$ State of Agile Report prepared by in 2016 by VersionOne. The parameters most subject to improvement are: the ability to manage changes (observed in $87 \%$ of cases); increased productivity $(85 \%)$; increase in the transparency of projects $(84 \%)$; reduction in the implementation time (79\%); reduction of project risks (77\%). The comparison of the effectiveness of Agile teams and teams working on all other methods of product / service development are: Productivity $+27 \%$; Shift in terms of implementation $30 \%$; the number of defects per request $-70 \%$; development cost $-40 \%$ [2].

In this paper, the term Fintech (financial-technological) means an industry combining the sectors of financial services and modern IT products. The main players in this

\footnotetext{
Corresponding author: vorontsovde@gmail.com
} 
market include technology companies and classical financial institutions: banks, insurance and investment companies. All of them either create themselves or use third-party innovations to improve their work and make life of clients easier [3].

Under the term Agile development we mean a set of innovative modern ways of the development of IT products [4].

Today in Russia, agile development approaches are widely used in many fintech companies, but the greatest development is manifested by the industry leaders: Sberbank (state participation) and Alfa-Bank (private bank) [5].

Agile approaches are not a fintech solution itself, but a set of methods and practices designed to manage and create fintech products (mobile, virtual and augmented reality applications, front-end and backend solutions). The most commonly used agile development methodologies in Fintech (Scrum, Kanban, etc.) are aimed to minimize risks reducing development parts to a series of short cycles called iterations, which usually last from two to three weeks.

Accordingly, in this article, under the Agile transformation of a fintech company, we mean a deep reorganization of the organizational structure, a transition to an agile methodology of project management and a change in company corporate culture, as a result of which it will be able to work on Agile principles.

\section{Results and discussion}

\subsection{Starting conditions for Agile transformation of a fintech company}

The starting condition for launching the Agile transformation of fintech companies is the awareness of the position of a company at the current moment in time and the target place where it is necessary to move. The value attitudes of a fintech company should be taken into account in the context of the market and in the planning horizon of the strategy of a company. Most companies value the predictability of product delivery or the ability to adapt to changes and this has negative consequences. The more the system is tuned for predictability, the more difficult it is to change it. On the contrary, the more adaptability is attached to a system, the less predictable it is.

Moreover, it is necessary to take into account the essence of the value of a product for ta client (emergent ecosystem - an open ecosystem), or just focus on performance of assumed functions (convergent ecosystem - a closed ecosystem) [6].

The entire process of Agile transformation of a fintech company includes the creation of teams, culture, structure and management methodology that are based on the principles of Agile, as well as the definition and implementation of those metrics that are critical for a company as a starting point as they will be used to assess progress and track improvements made during transformation.
The agile transformation strategy will ultimately depend on the value system adopted by the team of a company and the needs and values of the customers.

\subsection{Specifics of Agile transformation depending on the scale of a Fintech company}

According to the size of a Fintech company, the Agile transformation of two types of companies should be considered separately: large companies such as classic banks, insurance and investment companies with more than 100 employees. The second type of companies is small, falling under the criteria of attribution to small businesses, as well as startups [7].

In most cases in small companies Agile transformation does not cause difficulties, since the change in structure and the introduction of agile methodologies is carried out by team building, training and adopting new development approaches. However, in large fintech companies, with a complex hierarchical structure and a heavy "legacy" in the form of an outdated information and technological architecture, changes need to be planned and organized in detail in order to eliminate the risks of loss of investment and effort invested in making changes that will create value for a client and therefore, for business, which will truly enable a fintech company to become flexible and adaptable to changes.

Contrary to established stereotypes the process of agile transformation of a large fintech company although follows the principles of the agile manifest, has little to do with so called management approaches of agile project. The agility of a solid company does not come from product separation, the implementation and ceremonies, but begins with a strategy for the management of internal investments and implementation of specific measures to develop a company culture. The main condition for the success of Agile transformation is not methods, not technology or experience, but company culture.

First of all the agile transformation of a large Fintech company is the work on the transition to a new structure and transformation of a company culture from a culture of control to a culture of development. Accordingly, this is the creation of effective self-organizing teams, the formation of a list of changes/backlog and the regular creation and setting of increments of a proven and workable software product. A fintech company-wide, this means to create chains of loosely coupled teams, measure team throughput, not team productivity, coordinate dependencies, work out negative impacts, continuously and rapidly improve products and processes through external and internal innovations, as well as quick product launch to the market [8].

\subsection{Change in company culture of a Fintech company during Agile transformation}

During the process of Agile transformation, a company culture is transformed according to the principles of Agile. This is a complex and risky process, as it involves a fundamental change in processes, as well as external and internal motivation of employees. In this case, Agile principles act as a transformation tool. 
The culture change involves the creation of stable agile teams that are focused on a single project/service or business task. They do not switch between different approaches, as the culture of Agile does not involve switching to parallel or related projects and disintegration.

The advantages of cultural change appear in the long term and lead to access amplification of development teams, more opportunities for creativity, minimization of excessive control and micromanagement from a higher level. However, during the first period of company restructuring, productivity may decline as teams adapt to new principles and processes.

\subsection{Change in the organizational structure of a Fintech company during the process of Agile transformation}

As a part of the Agile transformation, a large-scale revision and change of the organizational structure of the management of a Fintech company is carried out. All elements are transformed by their one-time transition to a new state.

The organizational and functional structure of a company (functional mines/wells) is replaced by Agile organization with the following basic units: crossfunctional teams, chapters (groups of specialists in one area of competence) and tribes (groups of interconnected teams formed for a specific product or business purpose). Overall responsibility for the business outcome rests on the tribe manager/board member of a fintech company involved in Agile.

Figure 1 shows the functional structure of the created Agile organization of a Fintech company

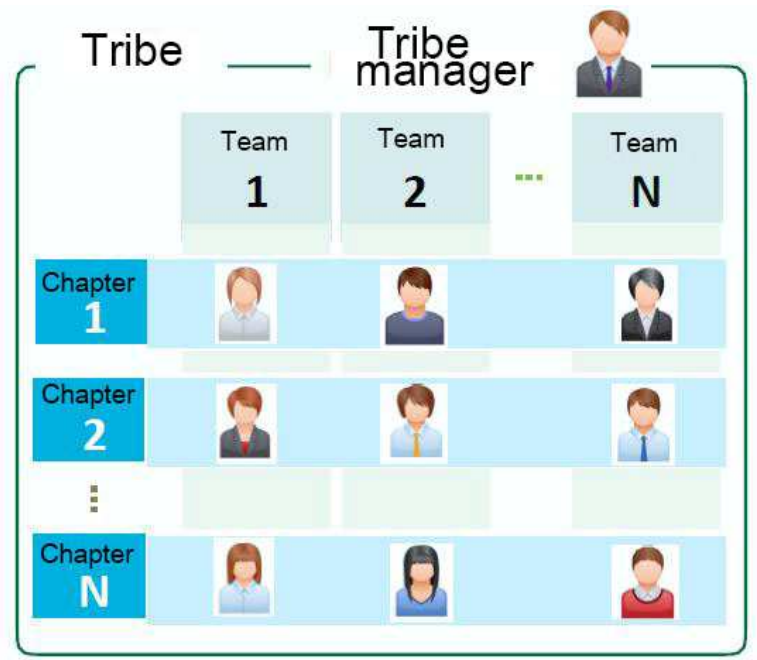

Figure 1. Agile organization structure

The size of the organizational units of an Agile organization must provide effective human communication and minimize bureaucracy. The number of tribes is not more than 150 people. The limitation is based on "Dunbar's number. In cases of exceeding the maximum tribe size or when close coordination of teams is required, the teams are combined into virtual clusters of up to 150 people, and then the tribe can be increased to 1500 people. [9].

The size of a chapter and a team should be no more than 9 people; the limit is based on the "Miller number".

The basic principle of tribe formation is selfsufficiency to meet a specific need.

According to the specifics and types of tasks there are two types of tribes and teams in a Fintech company: customer-oriented (they implement elements of business tasks and build an end-to-end customer experience) and platform, which create the basic modules of a product and ensure its architectural integrity and sustainability. A complex multi-level hierarchical management system is transformed into a flat structure with no more than three levels of the management hierarchy, excluding the board or CEO of a company.

Every level of management has the maximum level of independence in decomposition and determination of the approach and method of implementation of the task assigned to it. The setting of tasks is carried out according to the "What/How" principle, in which the higher level sets the task in the form of "what to do" or "what goal needs to be achieved" and the lower level itself determines "how" to do.

Figure 2 shows the final version of the Agile transformation of the hierarchical structure of a fintech company.

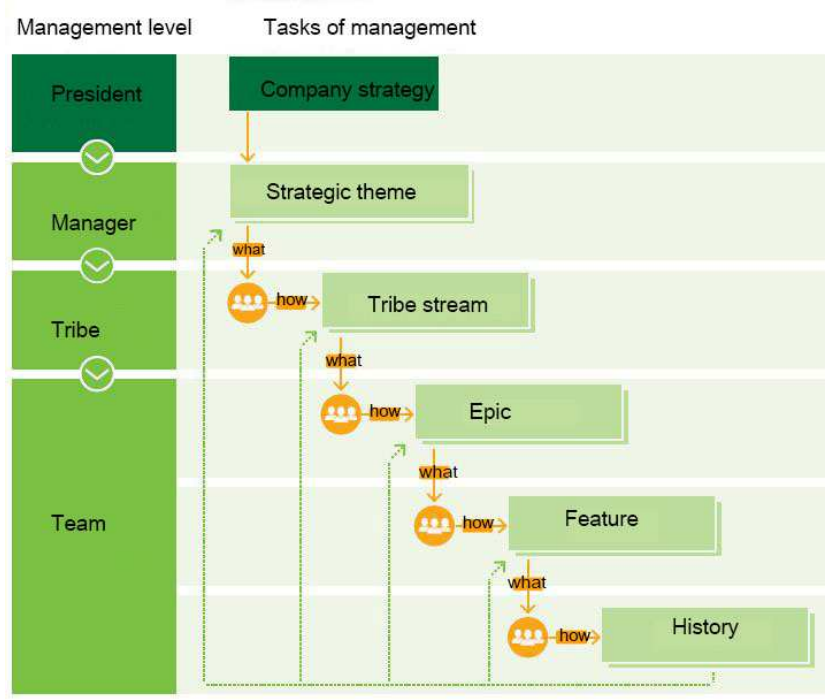

Figure 2. Hierarchical structure of Agile organization

The higher level does not participate in the tasks performed by lower level [10].

\subsection{Change in the project methodology of a Fintech company during the process of Agile transformation}

The process of agile transformation introduces a flexible methodology of project management both in the work of teams and at all levels of management of a Fintech company. It is necessary to note that there is no single Agile methodology. At the same time, various flexible methodologies or Frameworks are used. The most popular ones in the financial industry are Scrum, SAFe, eXtreme 
Programming, Feature Driven Development, Crystal, as well as all possible hybrid approaches.

Accordingly, the waterfall approach of project implementation and major changes with a long preparation process is replaced by a flexible MVP (minimum viable product) development approach and quick feedback from a client for further improvements of this product. The principle of the creation of a product is being introduced iteratively without the desire to create everything at once. Respectively, the product is created incrementally, from simpler to more complex.

During the introduction of agile methodology, a number of changes take place. The bureaucratic process of start and management of projects is being replaced by a release process, in which changes become a routine process and the basis of a Fintech company. The transition to Agile releases is carried out in stages, depending on the stage of transformation and overcoming the limitations of existing production processes.

Partial involvement of management and staff in projects is transformed into full-time work in one team or on a specific task.

The adoption or approval of all decisions by the management is replaced by an open collaborative environment, implemented through the development of trust, support and encouragement of openness, professionalism and reliability, as well as the widest possible delegation of authority at all levels. Control over the performance of tasks is carried out at product demonstrations and a quarterly review of results. The integrity of approaches to work and architecture and compliance with standards is supported by the chapter mechanism and/or controlled by technologists.

\subsection{Agile transformation stages of fintech companies}

Successful transformations undergo through a largescale and long path, consisting of conditional stages that can intersect with each other or be parallel.

A key step in the transformation is timely delivery of business value to a customer on a regular basis. The purpose is to reorganize the structure and approaches to the execution of project work. The most commonly used practice is to move from the "big bang" - large but infrequent releases/deliveries to small but regular deliveries or incremental product value. Transformation management is carried out in the same way.

Considering the experience of large organizations (Sberbank, Alfa-Bank, Diasoft and others), the Agile transformation of one company is different from others. At the same time, all considered companies went through the following stages:
The $1^{\text {st }}$ stage. Formation of the final vision of Agile transformation and initiation of changes

At the beginning, a company in general is considered in connection with the definition of business goals for the upcoming changes. The final vision determines the approach to the formation of change leaders, the sequence of their initial actions, the type of project management model, metrics, tools and methodology for the identification and measurement of improvements. The understanding of where a company is approaching is formed before the movement begins. It is foreseen in advance that the plan will be subject to constant changes, since it includes working management hypotheses, structure and metrics that a company is using and will be continually refined as it transforms.

Large companies use well-established approaches to coordinate teams together in order to increase their productivity in the definition of final concept.

\section{The $2^{\text {nd }}$ stage. Formation of a transformation team}

Agile transformation of a fintech company requires the implementation of changes in all key elements of organization structure and projects. Therefore, full management support is required. At this stage, the understanding and involvement of top managers in the course of what will happen is formed. The need for external consulting is explained.

\section{The $3^{\text {rd }}$ stage. Formation of the roadmap of Agile transformation}

It is the creation of a detailed but flexible action plan with terms and results that a company will receive in return for investment. Groups or divisions are also appointed that lead and set the pattern for transformation.

\section{The $4^{\text {th }}$ stage. Creation of a pilot transformation plan}

The process of Agile Transformation team constantly interacts with each other to plan, assess success and adjust the plan if it is necessary.

The main requirement for a team is to have a flexible 3-month plan and a creative view of the upcoming transformation. The 3 month plan is similar to flexible release planning. The plan lists all of the procedures and processes that will be affected by the changes over the next three months.

As a result, a team will prepare and launch a pilot project. The decision on the place and time of the pilot is made at the level of the president of a company. The results of a pilot will be a necessary basis for the identification and implementation of changes.

\section{The $5^{\text {th }}$ stage. Control over intermediate transformation results}

This stage provides the collection, preparation and training of leaders and teams of the first stages of 
transformation, which are constantly progressing, moving from one state to other.

As the teams develop the final state of the pilot project and subsequent changes are reached. Basic and key metrics are determined, measurements are taken regularly and openly and information about the resulting improvements is spread. Similarly to the cyclicality and frequency of the iterations established by the methodology, a periodic assessment of the achievement of transformation metrics is carried out. Based on the control, retrospectives are carried out and changes to the process are made.

\section{The $6^{\text {th }}$ stage. Adaptation and training}

At this stage, structure, management and metrics will begin to migrate into a coherent whole. An accessible internal base of best practices is being formed in a company. In the period of development and expansion of the scale of transformation, the centralized accumulation and use of the resulting best practices becomes a natural process.

A revision of the vision of the final state of changes is carried out based on the understanding of success in the Agile transformation process. Moreover, at this stage, new training and information materials, reminders for further actions and best practices of Agile transformation are created. In addition, the methods and approaches to adapt Agile coaches within a company are being developed, the level of development is regularly measured and work with attenuation and negative consequences are performed.

\section{The $7^{\text {th }}$ stage. Coordination of actions to the} business results of a fintech company

The main reason to start the Agile transformation process is the desire to improve significantly business results, so the organization begins to justify the investment by making assumptions, experimenting, demonstrating and declaring results, changing strategy depending on the lessons learned.

The main purpose is to build the correct sequence of the required results, as well as to ensure that the transformation actions correspond to the inherent business results.

\section{The $8^{\text {th }}$ stage. Coordination of transformation results to business purposes}

This stage includes tracking performance improvement towards desired business benefits and regular demonstration the positive dynamics of core business metrics to management.

The main purpose of this stage is to visualize a transparent and sustainable relationship between investment and achieved business results.

The 9th stage. Communication management and information support
This stage includes the transparent and ongoing communication in order to achieve success and overcome the difficulties faced by the transformation team. It also includes the creation of a positive atmosphere and energizes a team. The following formats are used: Roundtables of a transformation team with management, general meetings and other relevant communication channels. Due to the impact of the COVID-19 pandemic, face-to-face formats are being forcedly replaced by remote communication channels, video conferencing and webinars.

\section{The $10^{\text {th }}$ stage. Psychological safety of participants in the process of Agile transformation}

The transparent and regular motivational meetings and conversations with the participants in the changes are being held, mainly about the benefits that they will receive and their place in the new structure of a company. The transparency and reliability of the measurement of the achievements of each participant is provided.

The implementation of these stages allowed major players in a Fintech market to launch or implement successfully the process of Agile transformation, preventing a decrease in the efficiency of a company when implementing changes. At the same time, we note the lack of uniform approaches to the stages of transformation and, as a consequence, the presence of variability in the results for similar companies.

\subsection{Challenges and opportunities of Agile development in the Russian financial and technological segment}

Financial and technological companies, being in a highly competitive, fast-growing environment, are clearly aware of the need for faster time to decision and time to market, as the main condition for survival in the modern rapidly changing world of financial services and the expansion of ecosystem.

The challenges faced by financial and technological companies require from management not only an instant response during decision making, but also a quick implementation of financial services and products. To provide speed, not only an appropriate structure to ensure the implementation of flexible and proven, fast-paced approaches are needed, but the adoption by employees of a culture of development based on the Agile principles.

The traditional hierarchical structures and the waterfall project approach used by the classic players of the Fintech market came under pressure of new players and, as a result, began to adapt to the requirements of the time, absorbing Agile approaches, which have recently been included and supplemented in the PMI, IPMA standards and PRINCE2. It is important that the use of Agile is causing a cultural transformation within large banks, changing the attitudes of people towards information technology, project work and ecosystem development for the better.

In 1-2 years, the competition between traditional banks and companies in the financial and technological sector 
will intensify even more without a banking license. New and fast IT companies will try to squeeze classic players out of the market, so the Fintech market, the success of which depends on the speed of response to external challenges and customer-centricity, is doomed to Agile transformation of the management structure and corporate culture of companies. Therefore, the demand for Agile transformation and specialists capable of carrying out these changes will grow at priority rates in the next 2-3 years.

\section{Conclusion}

The limitations and consequences of the COVID-19 pandemic, the rapid growth of technological solutions, the development of product and information platforms, as well as the construction of ecosystems of products and services, created high uncertainty and development risks for startups and existing large fintech players. Taking this into account, they will make more and more qualitative and quantitative requirements both to the process and the results of launched or planned Agile transformations of their companies.

\section{References}

1. Fintech market development in Russia Retrieved from: https://www.finam.ru/analysis/forecasts/razvitie -fintex-rynka-v-rossii-neobanki-i-startapy20191211-142048/

2. The 10th report of the VersionOne company on the state of adaptive development methods Retrieved from: http://www.agile247.pl/wpcontent/uploads/2016/04/VersionOne-10thAnnual-State-of-Agile-Report.pdf

3. Russian fintech Retrieved from: https://iq.hse.ru/news/334262759.html

4. Wolfson B. Flexible project and product management. (SPb.: Peter, 2016).

5. Cases of agile transformation Retrieved from: https://vc.ru/hr/100793-keysy-agiletransformacii-chast-pervaya-banki

6. What determines the success of Agiletransformation Retrieved from:: https://pro.rbc.ru/demo/602b21df9a7947f6aa33 $\underline{8611}$

7. Agile Research Report in Russia 2020 Retrieved from: https://agilesurvey.ru/

8. Foundations of Agile-transformation Retrieved from:

https://habr.com/ru/company/rdtex/blog/452358 I

9. Experience in the implementation of flexible development methodology in the activities of retail and IT-blocks of the bank Retrieved from: http://www.reglament.net/bank/raschet/2017_5/ get article.htm? id=5360

10. Using the Agile-Approach in Business Practice Retrieved https://alprex.ru/stati/ispolzovanie-agile-podhodav-praktike-biznesa 